\title{
GABACULINE-RESISTANT MUTANTS OF CHLAMYDOMONAS REINHARDTII WITH ELEVATED GLUTAMATE 1-SEMIALDEHYDE AMINOTRANSFERASE ACTIVITY
}

\author{
by \\ ALBERT KAHN") and C. GAMINI KANNANGARA ${ }^{2)}$ \\ 1)Institute of Genetics, Øster Farimagsgade 2A, \\ DK-1353 Copenhagen $\mathrm{K}$ \\ and \\ ${ }^{2}$ Department of Physiology, Carlsberg Laboratory, \\ Gamle Carlsberg Vej 10, DK-2500 Copenhagen Valby
}

Keywords: $\delta$-Aminolevulinate synthesis, chlorophyll biosynthesis

\begin{abstract}
Gabaculine-resistant mutants were obtained from UV-irradiated Chlamydomonas reinhardtii by selection on agar plates containing 2 or $4 \mathrm{mM}$-gabaculine. Genetic analysis of two of the mutants showed that the mutations conferring gabaculine resistance lie in non-allelic nuclear genes. These genes, gab 1 and gab 2 are linked to their respective centromeres and not to each other. Glutamate 1-semialdehyde aminotransferase activity in the soluble protein fraction of these mutants and a third one was 1.5 to 4 fold higher than in the wild type. Gabaculine inhibited the aminotransferase activity in the extracts from wild type and all three mutant strains of algae.
\end{abstract}

\section{INTRODUCTION}

Chlorophyll biosynthesis is regulated primarily at the enzymic steps catalysing the synthesis of $\delta$-aminolevulinate (3). In Chlamydomonas (10) and in greening barley (5) the enzyme glutamate 1-semialdehyde aminotransferase catalyses the last step in $\delta$-aminolevulinate synthesis. DLgabaculine (3-amino-2,3-dihydrobenzoic acid) is a potent inhibitor of this enzyme (6). Gabaculine inhibits $\delta$-aminolevulinate synthesis in Chlorella extracts (11) and chlorophyll synthesis in algae and higher plants (2). During gabaculine inhibition of chlorophyll synthesis in barley leaves, glutamate 1-semialdehyde accumulated (6). Therefore it was concluded that glutamate 1-semialdehyde aminotransferase participates in the chlorophyll biosynthetic pathway (6). It thus became apparent that gabaculine-resistant mutants could carry mutations affecting the enzyme glutamate 1-semialdehyde aminotransferase. In this paper we report on three gabaculine resistant mutants in Chlamydomonas which overproduce glutamate 1-semialdehyde aminotransferase activity.

\section{MATERIALS AND METHODS}

\subsection{Chlamydomonas strains}

Wild type Chlamydomonas reinhardtii DAN-

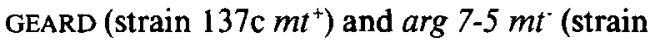


110) were generously supplied by ROLAND LOPPES and RENÉ MATAGNE, University of Liège. ElIZABETH HaRrIS at the Chlamydomonas Genetics Center, Duke University, kindly sent the following strains: $\mathrm{CC} 125$, (wild type $\left.m t^{+}\right)$; CC255, $\left(m t^{+}\right.$nic 13 msr 1 act 2 pyr 1 $\mathrm{Can}^{\mathrm{r}}$ ) and $\mathrm{CC} 631, \mathrm{mt}^{+}$nic 17 . The nicotinamide auxotropy of CC631 did not recombine with $\mathrm{mt}^{+}$, and $\mathrm{nic} 17$ therefore is allelic with or close to nic 7 . Using the strains $\mathrm{CC} 125, \mathrm{CC} 255$ and arg 7-5 mt, the strain X11-17A ( $\mathrm{mt}^{\circ}$ nic $13 \mathrm{msr}$ 1 act $2 \mathrm{Can}^{\mathrm{s}}$ ) was developed. The canavanine resistance of $\mathrm{CC} 255$ (gene designated as can 1) proved to be due to two, unlinked genes (each alone conferring partial resistance and one of them centromere-linked like can l), and pyr 1 has not been assayed in X11-17A.

\subsection{General conditions of growth}

The composition of the growth medium used in grams per litre was: $\mathrm{NH}_{4} \mathrm{Cl}, 0.5 ; \mathrm{CaCl}_{2}$. $2 \mathrm{H}_{2} \mathrm{O}, 0.05 ; \mathrm{MgSO}_{4} \cdot 7 \mathrm{H}_{2} \mathrm{O}, 0.30 ; \mathrm{K}_{2} \mathrm{HPO}_{4}$, $0.29 ; \mathrm{KH}_{2} \mathrm{PO}_{4}, 0.14$; Trizma Base, 2.42; $\mathrm{CH}_{3}$ $\mathrm{COONa} \cdot 3 \mathrm{H}_{2} \mathrm{O}, 2.0$; and a mixture of trace elements as given in (4). The $\mathrm{pH}$ of all the media was adjusted to 7.0. Solid media were obtained by the addition of $15 \mathrm{~g}$ of Difco Bacto-Agar per litre. Agar plates ( $9 \mathrm{~cm}$ in diameter) contained $25 \mathrm{ml}$ medium and were sealed with Parafilm during algal growth to prevent contamination. Stock cultures were maintained on agar slants in screw cap tubes with the medium augmented by $4 \mathrm{~g}$ per litre Difco Bacto-Yeast extract. All media were sterilized by autoclaving. Gabaculine, when desired, was added from a stock solution after partial cooling of the medium.

The algae were cultured at 20 to $22{ }^{\circ} \mathrm{C}$ in constant light (ca. 100 foot candles meter reading) supplied by a mixture of $20 \mathrm{~W}$ cool and warm white fluorescent tubes. Growth in liquid medium occurred in $35 \mathrm{ml}$, closed screw cap Eltang tubes containing 11 to $21 \mathrm{ml}$ medium. The tubes were swirled manually or with a Whirlimixer once or twice daily during the growth period. Maximum titers of $5 \times 10^{6}$ to $10^{7}$ cells per $\mathrm{ml}$ were routinely achieved, with the greatest density of algae resulting in tubes containing $11 \mathrm{ml}$ of medium. Cells were counted with a hæmocytometer.

\subsection{Mutagenesis of wild type, gabaculine-} sensitive (Gabs) Chlamydomonas with UV light and selection of gabaculine-resistant $\left(\mathbf{G a b}^{5}\right)$ mutants

Strain $137 \mathrm{c} m t^{+}$was cultured in liquid medium into exponential phase. Aliquots $(0.1 \mathrm{ml}$, $5 \times 10^{4}$ colony forming units) were spread on either 2 or 4 mM-gabaculine-containing plates. Six plates with $2 \mathrm{~mm}$-gabaculine and 8 with 4 mM-gabaculine were used. The algae were then irradiated for 30 seconds with a Hanovia Letharay lamp (light dose rate, $1.7 \mathrm{~W} \times \mathrm{m}^{-2}$ ). The plates were maintained in darkness during the following day to prevent photoreactivation. Survival after the UV irradiation was $34 \%$. Thus $1.7 \times 10^{4}$ mutagenized colony forming units per plate were screened for gabaculine resistance. Thirteen days after plating there were no macroscopic colonies on the $4 \mathrm{~mm}$-gabaculine plates. On the $2 \mathrm{~mm}$-gabaculine plates there were 27 large dark green colonies and a very large number of microscopic colonies. When the $4 \mathrm{~mm}$ gabaculine plate containing UV-irradiated cells was incubated for a longer period, 9 colonies became macroscopically visible and green. Five of the largest and 10 other colonies presumed to be $\mathrm{Gab}^{r}$ were picked from the $2 \mathrm{mM}$-gabaculine plates and transferred to a $4 \mathrm{~mm}$-gabaculine plate. As controls, three colonies of wild type $\left(137 \mathrm{c} m t^{+}\right)$Chlamydomonas were also transferred to the same plate. After 5 days, algae from all 5 of the largest and 7 of the other 10 presumed $\mathrm{Gab}^{\mathrm{r}}$ colonies showed growth with a muddy green aspect. The control streaks failed to grow and were bleached. Thus 2 to 3 per $10^{4}$ colony forming units that survived mutagenesis on 2 mM-gabaculine plates showed gabaculine-resistance and were presumed to be mutants.

Two of the largest colonies found originally on the $2 \mathrm{~mm}$-gabaculine plate were designated as gab 1 and gab 2, while one of the colonies on the 4 mM-gabaculine plate was designated as gab 3 . These were spread on 2 mM-gabaculine plates and a single colony resulting from each was isolated and gave rise to a stock culture. 


\subsection{Culture and harvest of algae for examination of glutamate 1-semialdehyde aminotransferase activity in vitro}

For each of the strains, 20 to 25 tubes, each containing $20 \mathrm{ml}$ (Table V) or $15 \mathrm{ml}$ (Figures 4 and 5) of liquid medium, were inoculated with $1 \mathrm{ml}$ from algal cultures approaching stationary phase. After 4 to 6 days growth, the cell numbers were determined with a hæmocytometer. The algae were then sedimented by centrifugation in a Sorvall SS34 rotor at $5000 \mathrm{rpm}$ for 5 minutes. The supernatants were decanted and the pelleted cells from each strain were resuspended with a Whirlimixer, pooled and centrifuged again. Thereafter, the pellets were stored in a deep freezer until extraction.

\subsection{Breaking of Chlamydomonas cells and isolation of the soluble protein fraction}

The frozen pellets ( 1 to $3 \times 10^{9}$ cells, ca 0.5 to $1 \mathrm{ml}$ packed volume) were thawed and suspended in three $\mathrm{ml}$ of ice cold medium containing 0.1 M-Tricine- $\mathrm{NaOH}, \mathrm{pH}$ 9.0, $0.3 \mathrm{M}$-glycerol, 25 $\mathrm{mM}-\mathrm{MgCl}_{2}$ and $1 \mathrm{~mm}$-dithiothreitol. The cell suspensions were passed through an ice cold French pressure cell at 2200 psig. Cell walls, membranes and other insoluble material were removed by centrifugation at $140000 \mathrm{~g}$ for 30 minutes at $4^{\circ} \mathrm{C}$. The supernatant was used in the enzyme assays.

\subsection{Glutamate 1-semialdehyde aminotransferase assay}

Each assay mixture (one $\mathrm{ml}$ ) contained 0.1 M-Tricine-NaOH, pH 8.0, 0.3 M-glycerol, 25 $\mathrm{mM}-\mathrm{MgCl}_{2}, 1 \mathrm{~mm}$-dithiothreitol, $5 \mathrm{~mm}$-levulinate and 0.5 to $3.8 \mathrm{mg}$ soluble protein. Appropriate volumes of stock solutions of glutamate 1 -semialdehyde, synthesized as in (6), were added to each assay to give a concentration of 0.1 (Table V) or $0.2 \mathrm{~mm}$ (Figures 4 and 5). The semialdehyde concentrations in the stock solutions were determined using Ehrlich's reagent, as described in (6). Gabaculine, when used, was added from a 10 or $100 \mu \mathrm{M}$-aqueous stock solution to give the desired concentrations. Assay mixtures were incubated for either 20 or 40 minutes at $28^{\circ} \mathrm{C}$ on a shaker in a water bath.
Reactions were terminated by adding $25 \mu$ l of ice cold $70 \%$ perchloric acid per assay. Precipitated protein was removed by centrifugation and the supernatant transferred into a graduated tube. The $\mathrm{pH}$ was adjusted to 6.9 using $0.5 \mathrm{M}-\mathrm{Na}_{3} \mathrm{PO}_{4}$ and in case of overshoot with $0.5 \mathrm{M}-\mathrm{NaH}_{2} \mathrm{PO}_{4}$. Thereafter, to each tube, $100 \mu$ l of ethyl acetoacetate was added before heating for 20 minutes in a boiling water bath to produce the $\delta$ aminolevulinate pyrrole. The tubes were then cooled to room temperature and the volume of liquid per tube adjusted to $1.5 \mathrm{ml}$ with water before mixing with $1.5 \mathrm{ml}$ of modified Ehrlich's reagent (9). Twenty minutes later the absorption spectra were recorded from 400 to $650 \mathrm{~nm}$ (Table V) or from 400 to $750 \mathrm{~nm}$ (Figures 4 and 5) with an Aminco DW2 spectrophotometer. The amounts of $\delta$-aminolevulinate formed were determined taking the molar extinction coefficient at $553 \mathrm{~nm}$ as $7.2 \times 10^{4} 1 \times \mathrm{M}^{-1}$ for a light path length of one $\mathrm{cm}(9)$.

Unincubated, complete assay mixtures served as the spectrophotometric references for obtaining the data in Table V. Results in Figures $\mathbf{4}$ and 5 rest on spectrophotometry with water as the reference. Accordingly, the absorbances at $\mathbf{5 5 3}$ $\mathrm{nm}$ had to be corrected to eliminate nonspecific contributions from Ehrlich's reagent, the algal extracts and glutamate 1-semialdehyde pyrrole. This was achieved by using equation 5 , as derived below:

1) $A_{553}^{o b s}=A_{553}^{A L A}+A_{553}^{n s}$

2) $A_{525}^{\text {obs }}=A_{525}^{A L A}+A_{525}^{\text {ns }}$

3) $\mathrm{A}_{553}^{\mathrm{ALA}}=(1.54) \mathrm{A}_{525}^{\mathrm{ALA}}$, (reference 9)

4) $\mathrm{A}_{553}^{\mathrm{ns}}=(1.1) \mathrm{A}_{525}^{\mathrm{ns}}$, (see below)

where the superscript obs refers to the observed absorbances, and ALA and ns refer to the contributions of $\delta$-aminolevulinate pyrrole and of non-specific compounds, respectively, to the absorbances; the subscripts indicate wavelengths in nanometers.

Combining and simplifying the 4 simultaneous equations yields:

5) $\mathrm{A}_{553}^{\mathrm{ALA}}=3.50 \mathrm{~A}_{553}^{\mathrm{obs}}-3.85 \mathrm{~A}_{525}^{\mathrm{obs}}$

The third ciphers of the constants in equation 5 are not significant.

The constant, 1.1 , in equation 4 is based on results of control assays run simultaneously with those shown in Figures 4 and 5. Assays with algal extracts ( 0.2 to $0.4 \mathrm{ml}$ additions) and no gluta- 
mate 1-semialdehyde gave absorbances at 553 $\mathrm{nm}$ ranging from 0.04 to 0.08 and $\mathrm{A}_{553} / \mathrm{A}_{525}$ ranging from 0.95 to 1.03 . An assay with glutamate 1 -semialdehyde at the concentration used throughout (and no algal extract) gave an absorbance of 0.06 at $553 \mathrm{~nm}$ and $A_{553} / A_{525}$ equal to 1.22 . (We note, in passing, that these parameters are not constant for glutamate 1-semialdehyde in crude, acidic preparations stored at -18 ${ }^{\circ} \mathrm{C}$; both $\mathrm{A}_{553}$ and $\mathrm{A}_{553} / \mathrm{A}_{525}$ decrease with time). Thus, 1.1 is a reasonable approximation of the mean $A_{553} / A_{525}$ for the demonstrated sources of nonspecific absorption, whose contributions to $A_{553}$, when each is assayed alone, are similar.

\subsection{Genetic analyses}

Strains were crossed and zygospores matured and germinated by methods that in all essential details are standard (7), except that mature zygospores sometimes were stored in darkness at $4{ }^{\circ} \mathrm{C}$ for up to 6 months. Dissections of tetrads were performed with a micromanipulator on agar slabs with complete medium. The resultant colonies were transferred as streaks to a master plate.

Segregations of genetic markers were determined after replication to various media. The media were supplemented, as appropriate, with the following compounds in $\mathrm{mg}$ per litre : $\mathrm{L}(+)$-arginine $\cdot \mathrm{HCl}, 50$; nicotinamide, 1 ; L-methionine D,L-sulphoximine, 500; cycloheximide, 10; and 3-acetylpyridine, 15 to antagonize nicotinamide and sharpen the Nic phenotype. Gabaculine was used at various concentrations.

\section{RESULTS AND DISCUSSION}

\subsection{Phenotypes of gabaculine-resistant mutants}

\subsubsection{Initial characterization of two $G a b^{r}$ mutants}

Liquid cultures of mutant strains gab 1, gab 2 and wild type $\left(137 \mathrm{c} m t^{+}\right)$were diluted and aliquots spread on sectors of $0,2,3$ and 4 mM-gabaculine plates. Five and 14 days after plating, the number of visible colonies on the plates were counted (Table I). No colonies of wild type cells appeared up to 14 days after
Table I. The growth of wild type and two gabaculine-resistant mutants of Chlamydomonas on agar plates containing different gabaculine concentrations.

Dilute cell suspensions were spread on sectors of the plates.

\begin{tabular}{llcll}
\hline & \multicolumn{4}{c}{$\begin{array}{c}\text { Number of visible colonies 5 days } \\
\text { after spreading cells on plates } \\
\text { containing gabaculine* }\end{array}$} \\
\cline { 2 - 5 } Strain & $0 \mathrm{mM}$ & $2 \mathrm{mM}$ & $3 \mathrm{mM}$ & $4 \mathrm{mM}$ \\
\hline Wild type & 13 & 0 & 0 & 0 \\
$\begin{array}{l}\left.\text { (137c } m t^{+}\right) \\
\text {gab 1 }\end{array}$ & 30 & $22(4)$ & $1(1)$ & 0 \\
gab 2 & 16 & 9 & 6 & $0(2)$ \\
\hline
\end{tabular}

*In parentheses are given the number of additional colonies found two weeks after plating.

plating on gabaculine-containing agar, while gab 1 and gab 2 cells gave rise to colonies on 2 and 3 mM-gabaculine-agar within 5 days, confirming their resistance. The mutant cells produced fewer colonies on 3 and $4 \mathrm{~mm}$ than on 2 mM-gabaculine-agar, indicating that they are not fully resistant to high concentrations of the compound. The growth of $\mathrm{Gab}^{r}$ colonies on gabaculine-containing plates was retarded in comparison with gabaculine-free plates.

\subsubsection{Effect of gabaculine on increase in cell number and chlorophyll synthesis of wild type and Gabr strains in liquid cultures}

Growth of $\mathrm{Gab}^{\mathrm{r}}$ and $\mathrm{Gab}^{\mathrm{s}}$ cells in $11 \mathrm{ml}$ liquid cultures with various concentrations of gabaculine was studied. Gab ${ }^{\mathrm{r}}$ segregants from crosses of the gab 1 and gab 2 strains with X11-17A (section 3.2) were compared with wild type $\left(137 \mathrm{c} \mathrm{mt^{+ }}\right), \mathrm{Gab}^{\mathrm{s}}$ algae. The number of cells per $\mathrm{ml}$ of culture after $0,2,3$ and 4 days of growth and chlorophyll concentrations (1) after 4 days were determined. The results are presented in Figure 1 (wild type, Gab), Figure 2 ( $g a b 1$ segregant, $\mathrm{Gab}^{\mathrm{r}}$ ), and Figure 3 (gab 2 segregant, $\mathrm{Gab}^{\mathrm{r}}$ ). Gabaculine up to $2 \mathrm{~mm}$ (or even $4 \mathrm{mM}$, data not shown) did not affect the increase in cell number (one to three doublings) during the first two days of culture in any of the three strains. 


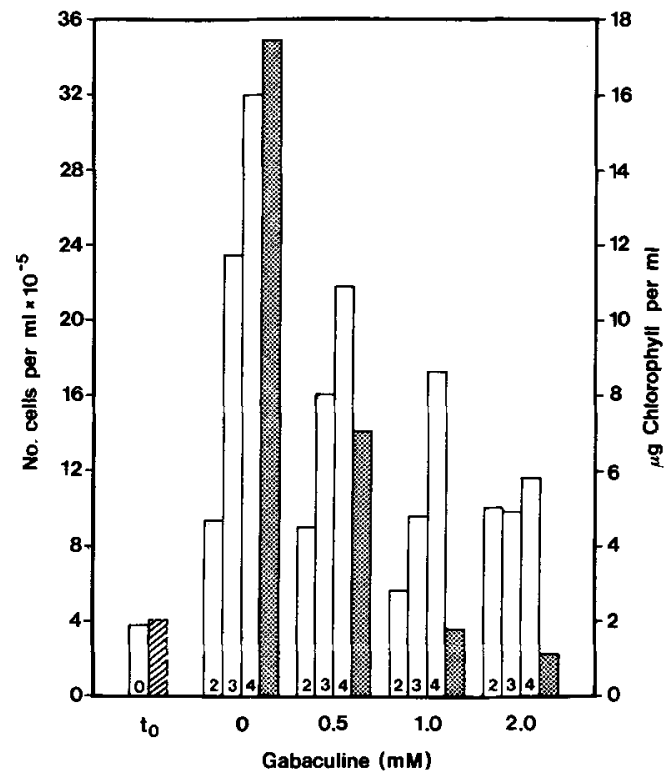

Figure 1. Inhibition of cell division and chlorophyll synthesis in wild type cells of Chlamydomonas reinhardtii by gabaculine.

One $\mathrm{ml}$ of cells of the strain $137 \mathrm{c} m t^{+}$approaching stationary phase were added to $10 \mathrm{ml}$ liquid culture media to give $3.8 \times 10^{5}$ cells per $\mathrm{ml}$ and $0,0.5,1.0$ or 2.0 mM-gabaculine. The concentration of cells in the cultures were determined after 2,3 and 4 days of growth. These are shown as bars with numbers corresponding to the days after time zero $\left(t_{0}\right)$. Chlorophyll concentrations (stippled bars) were determined four days after inoculation. The concentration of chlorophyll at $t_{o}$ (hatched bar) was calculated by assuming that the chlorophyll content per cell was the same as in cells of the experiment grown for $\mathbf{4}$ days without gabaculine.

Thereafter, the increase in cell number of $\mathrm{Gab}^{\mathrm{s}}$ was inhibited progressively by increasing gabaculine concentrations, reaching complete inhibition at $2 \mathrm{~mm}$-gabaculine. This suggests that cell doublings during the first two days already were potentiated in the inocula and thereby insensitive to inhibition by gabaculine. Compared with wild type the cell division of the $g a b l$ and $g a b$ 2 segregants was less severely inhibited by increasing gabaculine concentrations. Increase in chlorophyll in wild type cultures was inhibited $70 \%$ by $0.5 \mathrm{~mm}$ and $100 \%$ by 1.0 and 2.0 mM-gabaculine. Gabaculine at $0.5 \mathrm{~mm}$ had little

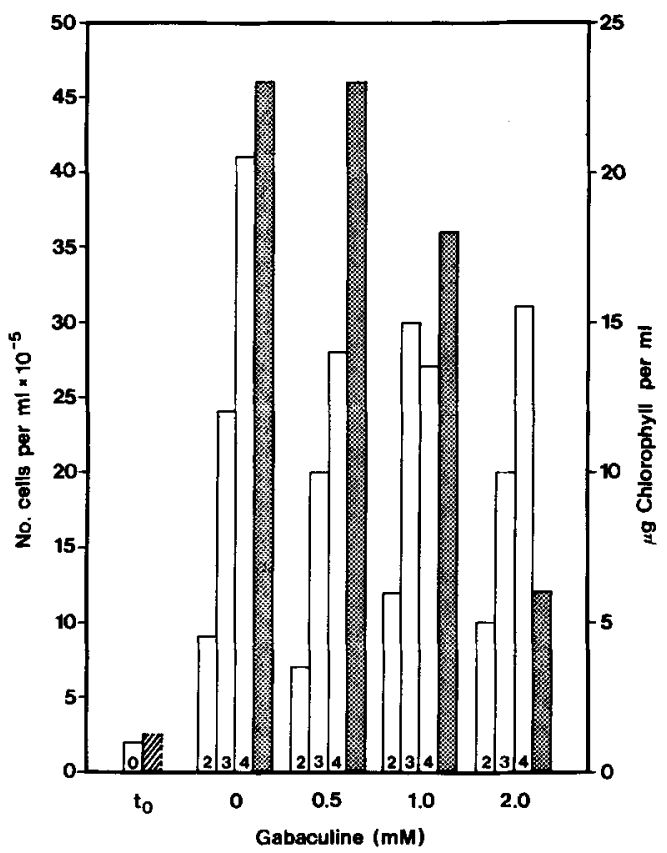

Figure 2. Effect of gabaculine on cell division and chlorophyll synthesis in mutant cells of Chlamydomonas carrying the gab 1 gene.

Details as in the legend to Figure 1, except that cultures contained $2.1 \times 10^{5}$ cells per $\mathrm{ml}$ at $\mathrm{t}_{\mathrm{o}}$.

or no inhibitory effect on chlorophyll synthesis in the gab 1 and gab 2 segregants. However, at 2 mM-gabaculine, chlorophyll synthesis was inhibited 60 to $75 \%$ in these two $\mathrm{Gab}^{\mathrm{r}}$ mutants.

\subsection{Genetic analysis of gabaculine-resistant mutants gab 1 and gab 2}

The mutant gab 1 strain was crossed with arg $7-5 m t$ and 32 tetrads were dissected. After a period of growth, the meiotic products were replicated onto non-supplemented, arginine, and arginine plus $2 \mathrm{~mm}$-gabaculine-containing plates. None of the tetrads gave rise to $2 \mathrm{Arg}^{+}$and $2 \mathrm{Arg}$ colonies. Most of the meiotic products which did not form colonies or did not survive replication were, by deduction, Arg. Growing adequately for classification were $52 \mathrm{Arg}^{+}, 25$ of which were resistant to gabaculine, and $16 \mathrm{Arg}$, none of which showed gabaculine resistance. Fifteen tetrads were dissected from the cross gab 


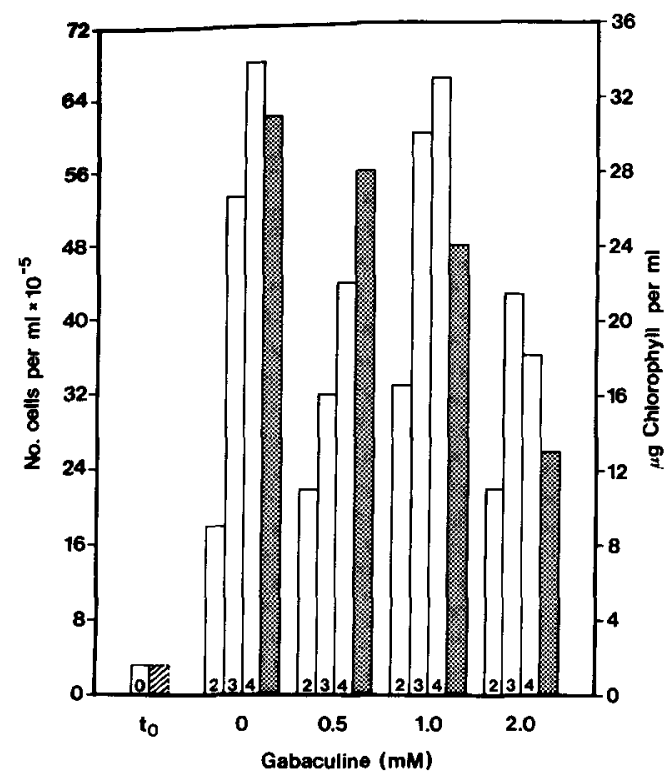

Figure 3. Effect of gabaculine on cell division and chlorophyll synthesis in mutant cells of Chlamydomonas carrying the gab 2 gene.

Details as in the legend to Figure 1, except that cultures contained $3.3 \times 10^{5}$ cells per $\mathrm{ml}$ at $\mathrm{t}_{\mathrm{o}}$.

$2 \times \arg 7-5 m t$. Only one tetrad gave $2 \mathrm{Arg}^{+}$and $2 \mathrm{Arg}$ colonies. Among the meiotic products that grew well, 27 were $\mathrm{Arg}^{+}$and $7 \mathrm{Arg}$. Of the arginine prototrophs, 9 were resistant to $3 \mathrm{mM}$ gabaculine $\left(\chi^{2}=3.0 ; \mathrm{P}>0.05\right.$ for $1 / 2 \mathrm{Gab}^{\mathrm{T}}$ among the $\mathrm{Arg}^{+}$progeny). None of the arginine auxotrophs showed gabaculine resistance. From these experiments we concluded that both gab 1 and $g a b 2$ are Mendelian genes conferring gabaculine resistance. Among plausible explanations for the absence of diagnosed Arg $\mathrm{Gab}^{r}$ progeny are: 1) cells bearing $g a b 1$ or gab 2 mutant genes are blocked in arginine uptake and 2) $\mathrm{arg}$ 7-5 gab $I$ or gab 2 cells, for complex reasons, do not display the $\mathrm{Gab}^{\mathrm{r}}$ phenotype.

Tetrad analyses were also performed after crossing the gab 1 and gab 2 strains with the strain X11-17A. The latter strain carried marker genes nic $13, \mathrm{msr} l$ and act 2 . The linkage groups and the map distances of these genes from their centromeres are: nic 13, X, 4; $m s r 1, \mathrm{I},>50$; act 2 , VI, $>50$. The results (Table II) showed $85 \%$ ditype tetrads for the nic $13-$ gab 1 and nic 13
Table II. Tetrad analyses of progenies from crosses of gab 1 and gab 2 with the strain X11-17A.

Only tetrads with 4 surviving products and with 2:2 segregations of all the markers are represented.

The number of different types of tetrad

\begin{tabular}{llcc}
\cline { 2 - 4 } Loci & $\begin{array}{l}\text { Parental } \\
\text { ditype }\end{array}$ & $\begin{array}{c}\text { Tetra- } \\
\text { type }\end{array}$ & $\begin{array}{c}\text { Non-parent- } \\
\text { al ditype }\end{array}$ \\
\hline gab 1 - nic 13 & 8 & 2 & 3 \\
gab $1-$ msr 1 & 3 & 9 & 1 \\
gab 1 - act 2 & 1 & 12 & 0 \\
gab 2- nic 13 & 8 & 2 & 3 \\
gab 2-msr 1 & 2 & 10 & 1 \\
gab 2-act 2 & 1 & 9 & 3 \\
\hline
\end{tabular}

- gab 2 segregations. Eight to $31 \%$ ditype tetrads were found for segregation of $m s r 1$ or act 2 with the $g a b^{r}$ genes. In addition, a nic $13 \mathrm{gab} 1 \mathrm{mt}$ segregant from the gab 1 times $\times 11-17 \mathrm{~A}$ cross was backcrossed to wild type $\left(137 \mathrm{c} m t^{+}\right)$. The ratio of types of tetrad for the gab $1-$ nic 13 segregation from this cross was 3PD: 1T: 2NPD. These results indicate that both gabaculine-resistance genes are strongly centromere-linked.

A gab $1 \mathrm{mt}$ ' segregant from the progeny of the cross $g a b 1$ times X11-17A was crossed with the strain CC631 ( $\mathrm{mt}^{+}$nic 17). The products of the dissected tetrads were replicated to diagnostic media. The replica plate containing 3 mM-gabaculine and $1 \mathrm{mg}$ per 1 nicotinamide was examined 6,12 and 33 days after replication (Table III). Thereby, a time course for observable macroscopic growth of gabaculine-resistant segregants was obtained. By six days after replication many gabaculine-resistant streaks had not grown sufficiently to be recognizable as such, whereas after 12 days, classification was more reliable. Almost all streaks that were judged as possibly, but not surely, resistant 12 days after replication later proved to be resistant by growing more, while sensitive streaks remained essentially static. This cross gave further evidence for a $2 \mathrm{Gab}^{\mathrm{r}}$ to $2 \mathrm{Gab}^{\mathrm{s}}$ segregation and, thereby, that $g a b 1$ segregates as a single nuclear gene. Similar results were obtained upon crossing CC631 with a $\mathrm{gab} 2 \mathrm{mt}$ segregant from the cross of gab 2 with X11-17A (data not shown). Here 9 of the 10 dissected tetrads with all 4 products 
Table III. Development of the gabaculine-resistant phenotype of $g a b$ 1: variations in descriptions of tetrads with time after replication.

A meiotic segregant carrying $g a b 1 \mathrm{mt}^{-}$was crossed with the gabaculine-sensitive strain CC631. Only tetrads with 2:2 segregation for nic 17 are included here. $\mathbf{r}=$ good, dark green growth (Gabr phenotype). $s=$ very slow or no growth sometimes with bleaching (Gabs phenotype). $\mathbf{i}$ = growth characteristics intermediate between $r$ and $s$ classes.

Distribution of tetrad classes following replication to $3 \mathrm{~mm}$-gabaculine

Tetrad plus $1 \mathrm{mg}$ per I nicotinamide after:

\begin{tabular}{llcc}
\cline { 2 - 4 } diagnosis & 6 days & 12 days & 33 days \\
\hline $0 r+4 s$ & 4 & 0 & 0 \\
$1 \mathrm{i}+3 \mathrm{~s}$ & 2 & 0 & 0 \\
$1 \mathrm{r}+3 \mathrm{~s}$ & 5 & 3 & 0 \\
$1 \mathrm{r}+1 \mathrm{i}+2 \mathrm{~s}$ & 0 & 5 & 0 \\
$1 \mathrm{r}+2 \mathrm{i}+1 \mathrm{~s}$ & 0 & 0 & 1 \\
$2 \mathrm{i}+2 \mathrm{~s}$ & 2 & 0 & 0 \\
$2 \mathrm{r}+2 \mathrm{~s}$ & 0 & 5 & 10 \\
$2 \mathrm{r}+1 \mathrm{i}+1 \mathrm{~s}$ & 0 & 0 & 2 \\
\hline
\end{tabular}

surviving were classified 33 days after replication to $3 \mathrm{~mm}$-gabaculine as containing $2 \mathrm{Gab}^{r}$ and $2 \mathrm{Gab}^{\mathrm{s}}$ segregants. The remaining tetrad gave one or possibly two $\mathrm{Gab}^{\mathrm{r}}$ segregants.

For allele tests three pairs of segregants were chosen from the progenies of the crosses of gab 1 and gab 2 with X11-17 A or arg 7-5 mt. Crosses were made with these pairs, as designated in Table IV. Only tetrads giving $2 \mathrm{Nic}^{-:} 2 \mathrm{Nic}^{+}$or 2 Act $^{\mathrm{r}}: 2 \mathrm{Act}^{\mathrm{s}}$ products are included in the table; combining the data from the three crosses gave 32 tetrads fulfilling these criteria. Considering the gab 1 - gab 2 segregations, 13 of these tetrads were parental ditypes, 10 were tetratypes and 9 were non-parental ditypes. The presence of gabaculine-sensitive meiotic products in the tetratype and non-parental ditype tetrads established that $g a b 1$ and gab 2 are not allelic. Furthermore, the results indicate that $g a b l$ and gab 2 are not linked and are consistent with both gab genes being centromere-linked. Calculations by the method of PERKINS (8) using the data in Tables II and IV, suggest that $g a b l$ and gab 2 lie somewhere between 4 and 16 map units from their respective centromeres.

\subsection{Glutamate 1-semialdehyde amino- transferase activity in gabaculine-resistant mutants and wild type Chlamydomonas}

The extracts of soluble proteins from wild type Chlamydomonas $\left(137 \mathrm{c} m t^{+}\right)$showed low levels of glutamate 1 -semialdehyde aminotransferase activity. These extracts catalysed the synthesis of from less than 1 up to 1.7 nmoles of $\delta$-aminolevulinate per $\mathrm{mg}$ protein in 20 minute assays at $28{ }^{\circ} \mathrm{C}$ (Table $\mathrm{V}$ and Figure 4). The gabaculine-resistant mutants all showed elevated levels of glutamate 1-semialdehyde aminotransferase activity compared to the wild type on a per mg protein basis. The mutant gab 1 and the gab 1 segregant had ca 4-fold higher activity than the wild type, while the mutants gab 2 and gab 3 showed 2- to 3-fold increased activity, respectively, in 20 minute assays. Results of some $\mathbf{4 0}$

Table IV. Tetrad analyses of the progenies of 3 crosses between gab 1 and gab 2 . The tetrads are classified according to segregation of gabaculine resistance in tetrads with all four products surviving and with $2: 2$ segregations of the marker genes nic 13 or act 2 .

\begin{tabular}{llcl}
\hline & \multicolumn{2}{c}{ The number of different types of tetrad } \\
\cline { 2 - 4 } Cross & $\begin{array}{l}\text { Parental } \\
\text { ditype }\end{array}$ & $\begin{array}{l}\text { Tetra- } \\
\text { type }\end{array}$ & $\begin{array}{l}\text { Non-parental } \\
\text { ditype }\end{array}$ \\
\hline gab I $\mathrm{mt}^{+} \times$gab 2 act $2 \mathrm{mt}^{-}$ & 5 & 4 & 5 \\
gab $2 \mathrm{mt}^{-} \times \mathrm{gab} 1 \mathrm{nic} 13 \mathrm{mt}^{+}$ & 4 & 4 & 3 \\
gab 2 $\mathrm{tt}^{+} \times$gab $1 \mathrm{nic} 13 \mathrm{mt}^{-}$ & 4 & 2 & 1 \\
\hline Total & 13 & 10 & 9 \\
\hline
\end{tabular}


Table V. Glutamate 1-semialdehyde aminotransferase activities from wild type and gabaculine-resistant mutants of Chlamydomonas.

$\delta$-Aminolevulinate was determined after condensing to a pyrrole with ethyl acetoacetate and treating with Ehrlich's reagent according to MAUZERALL and GRANICK (9). An unincubated complete assay mixture served as reference during spectroscopy. The amount of soluble protein in $0.2 \mathrm{ml}$ extract used per assay corresponded to ca $10^{8}$ cells.

Glutamate 1-semialdehyde aminotransferase activity

\begin{tabular}{lccccc}
\hline & \multicolumn{2}{c}{ nmoles $\delta$-aminolevulinate formed in: } \\
\cline { 2 - 3 } \cline { 5 - 6 } Source of & \multicolumn{2}{c}{ 20 min assay } & & \multicolumn{2}{c}{40 min assay } \\
\cline { 2 - 3 } \cline { 5 - 6 } enzyme & assay & protein & & assay & Per mg \\
\hline wild type & 1.0 & 1.7 & & 2.3 & 3.8 \\
gab 1 & 6.2 & 6.5 & & 10.4 & 10.8 \\
gab 3 & 1.2 & 2.6 & & 2.3 & 5.0 \\
\hline
\end{tabular}

minute assays (Table $\mathrm{V}$ ) indicated that the formation of $\delta$-aminolevulinate continued unabated in the latter 20 minute parts of these incubations. Increasing amounts of the extracts added to the assays led to approximately proportional increases in the formation of $\delta$-aminolevulinate (Figure 4). From these observations it was concluded that the gabaculine-resistant mutants are overproducers of glutamate 1-semialdehyde aminotransferase activity. The elevated activity in the mutants could result from an increased transcription and/or translation of the aminotransferase gene (or genes) or from a more efficient, mutated enzyme.

Gabaculine strongly inhibited the glutamate 1 -semialdehyde aminotransferase activity in the extracts from the wild type, gab 1, gab 1 segregant, gab 2 and gab 3 strains (Figure 5). Since the actual amounts of enzyme in the crude preparations assayed are not known, it is hazardous to make detailed, quantitative comparisons on the extents of inhibition by the various concentrations of gabaculine. The slopes of the inhibition curves do not differ markedly, and we infer, therefore, that enzyme from wild type and from gabaculine-resistant strains has similar sensitivity to gabaculine. No good evidence for inhibition by the lowest assayed concentration of gabaculine $(0.25 \mu \mathrm{M})$ was obtained, but above 0.5

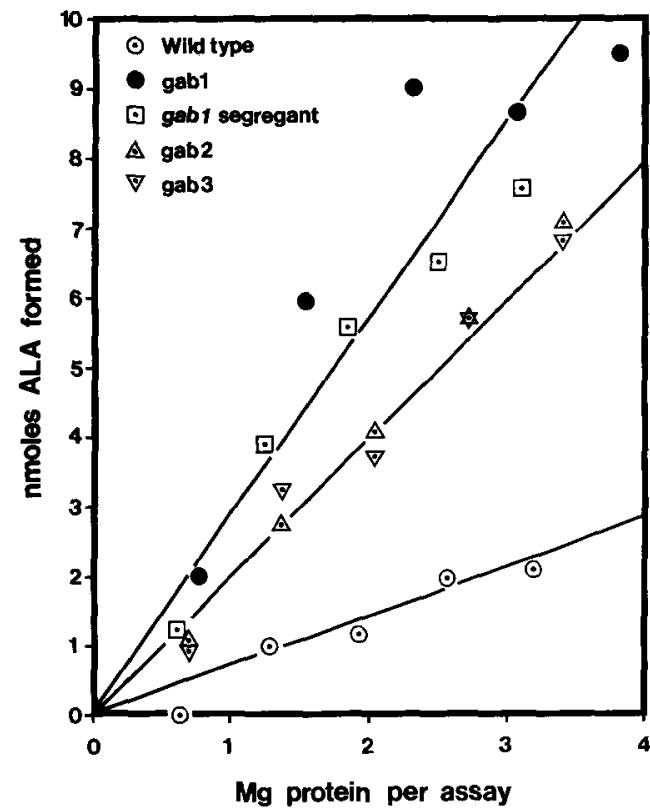

Figure 4. Elevated glutamate 1-semialdehyde aminotransferase activities in extracts from gabaculine-resistant mutants as compared with the activity in an extract from wild type $\left(137 \mathrm{c} m t^{+}\right)$Chlamydomonas.

Varying amounts of the extracts, in steps of $0.1 \mathrm{ml}$, were added to the assays which were terminated after $20 \mathrm{~min}$ incubation at $28^{\circ} \mathrm{C}$. The nmoles of $\delta$ aminolevulinate (ALA) formed were calculated from corrected absorbances at $553 \mathrm{~nm}$, as described in section 2.6. No significant difference between the results obtained with the gab 2 and gab 3 extracts was observed. Because the gabaculine resistance genes in the gab 1 and gab $l$ segregant algae are the same, a single line is also drawn through the points representing those extracts.

$\mu \mathrm{M}$-gabaculine, the $\delta$-aminolevulinate formed decreased in all the assays by what appears to be a constant amount per unit increase in gabaculine concentration.

Because the glutamate 1-semialdehyde aminotransferase activities of the $\mathrm{Gab}^{\mathrm{r}}$ mutants are sensitive to inhibition by very low concentrations of gabaculine in vitro, resistance of this enzyme is not likely to be the basis for the phenotypes of the mutants. The moderate elevations of extractable enzyme activities in the $\mathrm{Gab}^{\mathrm{r}}$ mutants as compared with wild type algae may be sufficient per se to explain the gabaculine 


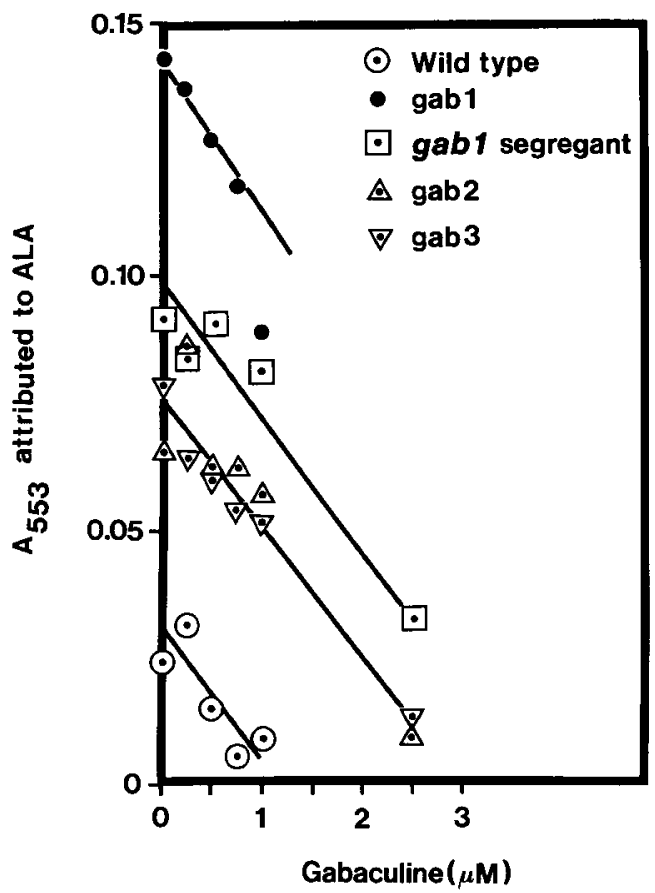

Figure 5. Inhibition by gabaculine of glutamate 1-semialdehyde aminotransferase activities in extracts of wild type $\left(137 \mathrm{c} \mathrm{mt}^{+}\right)$and gabaculine-resistant mutants of Chlamydomonas.

The following amounts $(\mathrm{mg})$ of protein were added in $0.2 \mathrm{ml}$ of extracts to the assays: wild type, 1.3; gab 1, 1.5; gab 1 segregant, 1.2; gab 2, 1.4 and gab 3, 1.4. The ordinate represents absorbance at $553 \mathrm{~nm}$ attributed to $\delta$-aminolevulinate (ALA) after correction as described in section 2.6. The values are proportional to amounts of ALA formed in the $\mathbf{2 0}$ minute assays.

resistance of the mutants. However, other possibilities should be considered.

Alternative bases for gabaculine resistance of the $\mathrm{Gab}^{\mathrm{r}}$ mutants could be either a reduction in permeability to gabaculine or an increased capacity to destroy the compound. The latter suggestions do not account for the elevated levels of glutamate 1-semialdehyde aminotransferase activities of the mutants. We have, of course, entertained the possibility that gab 1 , gab 2 and gab 3 are regulatory genes whose products have multiple roles, one of which is to control the level of activity of glutamate 1-semialdehyde aminotransferase.

\section{ACKNOWLEDGEMENTS}

We thank Ms Tove FrIIs for skilful technical assistance, Mrs. NINA RASMUSSEN for drawing the figures, and Dr. SIMON P. Gough and Professor DITER VON WETTSTEIN for critically reading the manuscript. Dr. ANDY WANG generously supplied the stock solution of trace elements used in the growth media.

\section{REFERENCES}

1. ARNON, D. I.: Copper enzymes in isolated chloroplasts: Polyphenoloxidase in Beta vulgaris. Plant Physiol. 24, 1-5 (1949)

2. FLINT, D. H.: Gabaculine inhibits $\delta$-ALA synthesis in chloroplasts. Plant Physiol. 75, suppl. p. 170 (1984)

3. GRANICK, S.: Magnesium porphyrins formed by barley seedlings treated with $\delta$-aminolevulinic acid. Plant Physiol. 34, xviii (1959)

4. Hutner, S. H., L. Provasoli, A. Schatz \& C. P. HASKINS: Some approaches to the study of the role of metals in the metabolism of microorganisms. Proc. Amer. Philosophical Soc. 94, 152-170(1950)

5. Kannangara, C.G.\&S. P. Gough: Biosynthesis of $\delta$-aminolevulinate in greening barley leaves: Glutamate 1-semialdehyde aminotransferase. Carlsberg Res. Commun. 43, 185-194 (1978)

6. Kannangara, C. G.\& A. SCHouboE: Biosynthesis of $\delta$-aminolevulinate in greening barley leaves. VII. Glutamate 1-semialdehyde accumulation in gabaculine treated leaves. Carlsberg Res. Commun. 50, 179-191 (1985)

7. LeVINE, R. P. \& W. T. Ebersold: The genetics and cytology of Chlamydomonas. Ann. Rev. Microbiol. 14, 197-216 (1960)

8. Perkins, D. L.: Biochemical mutants in the smut fungus Ustilago maydis. Genetics 34, 607-626 (1949)

9. MaUzerall, D.\&S. Granick: The occurrence and determination of $\delta$-aminolevulinic acid and porphobilinogen in urine. J. Biol. Chem. 219, 435-466 (1956)

10. Wang, W. -Y., D. -D. Huang, D. Stachon, S. P. Gough \& C. G. Kannangara: Purification, characterization and fractionation of the $\delta$ aminolevulinic acid synthesizing enzymes from light-grown Chlamydomonas reinhardtii cells. Plant Physiol. 74, 569-575 (1984)

11. Weinstein, J. D. \& S. I. Beale: Enzymatic conversion of glutamate to $\delta$-aminolevulinate in soluble extracts of the unicellular green alga Chlorella vulgaris. Arch. Biochem. Biophysics. 237, 454-464 (1985)

Accepted by $\mathbf{H}$. KLENOW 